\title{
ANALYSIS OF FEEDING MECHANISM IN MICROSTRIP PATCH
}

\section{ANTENNA}

\author{
Anchal Verma ${ }^{1}$, O.P. Singh ${ }^{2}$, Ganga Ram Mishra ${ }^{3}$ \\ ${ }^{I}$ Dept. of Electronics and Communication, Amity University, Lucknow \\ ${ }^{2}$ Dept. of Electronics and Communication, Amity University, Lucknow \\ ${ }^{3}$ Dept. of Electronics and Communication, Amity University, Lucknow
}

\begin{abstract}
This paper presents a comparative design between microstrip and coaxial feeding mechanism used in microstrip patch antenna along with the optimization of resonant frequency, return loss, Antenna impedance, VSWR, Gain etc. The Full wave analysis simulation is carried out in HFSS tool in the frequency range of 2-3 GHz i. e. in S band for Wi-fi application.
\end{abstract}

Keywords - Microstrip patch Antenna, Microstrip feeding, Coaxial feeding, Simulation Results.

$* * *$

\section{INTRODUCTION}

The patch antenna was first proposed in the early 1950 s but it was not used until 1970s when this type of antenna attracted main attention in commercial and defense purpose. Today Microstrip antenna is most widely used antenna because of its low cost, light weight, ease of fabrication, printed technology, conformable to planner and non planner surfaces, feed line and impedance matching network can be integrated, but having some drawbacks also like low gain and narrow impedance bandwidth typically less than $5 \%$, low efficiency, low power, High Q factor (greater than 100), poor polarization purity and spurious feed radiation[1,2]. In the high performance aircraft, space craft, missiles and satellites where size, cost, weight, performance, aerodynamics profile are constraints, a low profile antenna is required.

By increasing the height of substrate, we can increase the Bandwidth and Radiation efficiency but at the same time the surface waves comes in pictures which travel within the substrate and they scattered at the bends and surface discontinuity, at the truncation of dielectric and ground plane. This extracts the power from total available power, hence decreases the efficiency. The surface waves can be eliminated by using the cavity. By the Stacking method we can increase the Bandwidth. The matching between the Patch antenna and feed network is mainly depends on the feeding technique used for this. The substrate height should be of the order of $0.003<\mathrm{h}$ $<0.05$ of $\lambda$ to reduce the surface waves [3].

For the Coplanar application the microstrip feed is directly connected to the edge of the patch and coaxial feed is used otherwise. The position of feed point controls the impedance matching condition. The cross polarization is due to the undesired higher order modes generated in patch and is affected because of both electrical and geometrical parameters. Patch array provides much higher gain than a single patch antenna element so they are usually used in airplane and military applications. A wireless LAN is used as an extension to, or an alternative to the wired LAN. A single patch antenna provides a gain from 6-9 $\mathrm{dBi}[4-22]$.

\section{MICROSTRIP FEEDING TECHNIQUE}

In the Microstrip feeding technique, the feed line is quarter wavelength long which is used for the impedance matching between the $50 \Omega$ line impedance and the Patch Antenna impedance. This is easy to fabricate. Impedance matching is simple by controlling insert feed position. The spurious radiation is low ( nearly $-20 \mathrm{~dB}$ ) and have narrow bandwidth ( $1-5 \%)$.

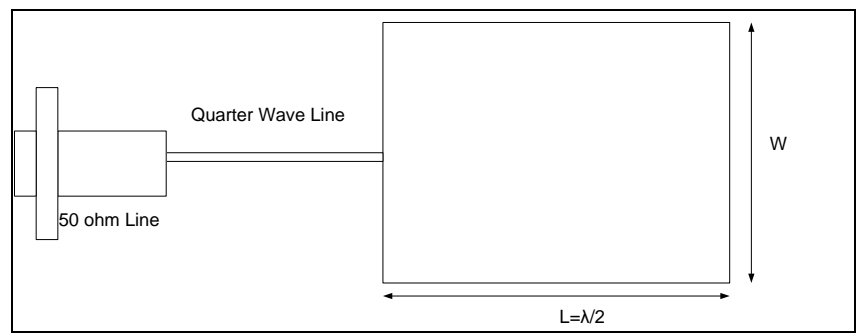

Fig 1: Microstrip feed Patch Antenna

The figure (1) shows the basic microstrip feed patch structure, having Length is equal to half of the resonating wavelength which is matched with $50 \mathrm{ohm}$ line through microstrip feed and Figure (2) represents the equivalent representation of microstrip feed. The feed contributes the inductive part to the patch. 


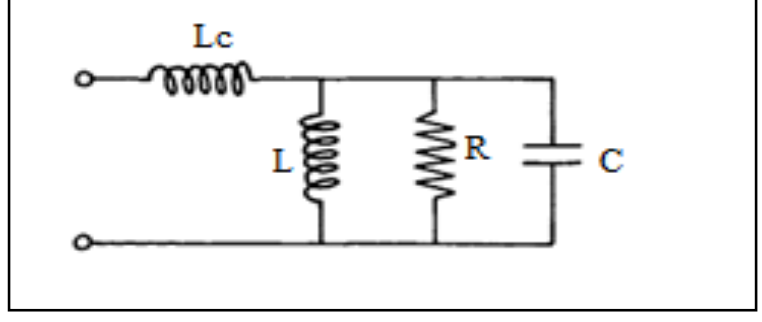

Fig 2: Equivalent of Microstrip feed Patch Antenna[3]

\section{DESIGN PROCEDURE OF PATCH ANTENNA}

In the Transmission line Model of Patch Antenna, the two slots are placed at half wavelength apart and the fringing field distribution is extended at length $\Delta \mathrm{L}[1]$.

$$
\Delta \mathrm{L}=0.412 h \frac{\left(\varepsilon_{e f f}+0.3\right)\left(\frac{w}{h}+0.264\right)}{\left(\varepsilon_{e f f}-0.258\right)\left(\frac{w}{h}+0.8\right)}
$$

The effective Dielectric constant is given by

$$
\varepsilon_{\text {eff }}=\frac{\varepsilon_{r}+1}{2}+\frac{\varepsilon_{r}-1}{2 \sqrt{1+\frac{12 h}{w}}}
$$

Width of Patch is:

$$
w=\frac{c}{2 f_{o} \sqrt{\frac{\varepsilon_{r}+1}{2}}}
$$

Hence the effective length of Patch is given by:

$$
\mathrm{L}_{\text {eff }}=L+2 \Delta \mathrm{L}
$$

Where,

$$
L_{e f f}=\frac{c}{2 f_{o} \sqrt{\varepsilon_{e f f}}}
$$

The input impedance of Patch is

$$
\mathrm{Z}_{\mathrm{a}}=90 \frac{\varepsilon_{r}^{2}}{\varepsilon_{r}-1}\left(\frac{L}{w}\right)^{2}
$$

The width of the Quarter wave line is given by:

$$
\mathrm{Z}_{\mathrm{T}}=\frac{60}{\sqrt{\varepsilon_{r}}} \ln \left(\frac{8 d}{w_{T}}+\frac{w_{T}}{4 d}\right)
$$

Where $\mathrm{Z}_{\mathrm{T}}$ is calculated as: $\mathrm{Z}_{\mathrm{T}}=\sqrt{50 * \mathrm{Z}_{a}}$
The length of Quarter line is $L_{T}=\frac{\lambda}{4}=\frac{\lambda_{0}}{4 \sqrt{\varepsilon_{\text {eff }}}}$

The width of $50 \Omega$ line is given by:

$$
\mathrm{Z}_{\mathrm{o}}=\frac{120 \pi}{\sqrt{\varepsilon_{r}}\left[1.393+\frac{w}{h}+\frac{2}{3} \ln \left(\frac{w}{h}+1.444\right)\right]}
$$

\section{COAXIAL PROBE FEEDING TECHNIQUE}

In the coaxial line feed, the inner conductor of the coax penetrates the substrate from the back of the ground plane without any contact with the ground plane by making a hole in it and is attached to the radiating patch, while the outer conductor is connected to the ground plane. Hence the coupling mechanism is purely inductive in nature. Spurious radiation is low ( nearly $-30 \mathrm{~dB}$ ) and bandwidth is also narrow (1-5\%). This is rejected in the space mission because possibly that it may break during the launching because of vibrations.

Radius of central conductor $=0.63 \mathrm{~mm}$

Radius of inner dielectric $\left(\right.$ Teflon $\left.\left(\varepsilon_{\mathrm{r}}=2.1\right)\right)=2.25 \mathrm{~mm}$

Radius of outer conductor $=2.5 \mathrm{~mm}$

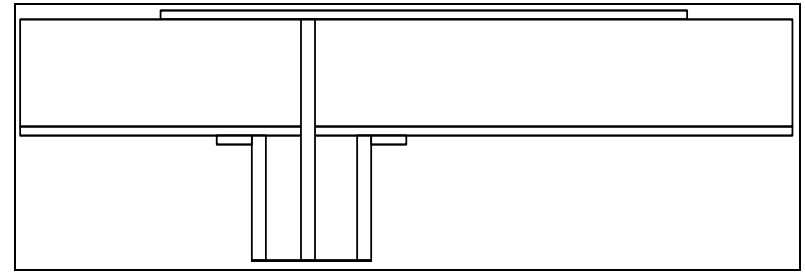

Fig 3: Coaxial feed Microstrip Patch Antenna

The figure(3) shows a coaxial feeding to the microstrip patch where the inner conductor connected with patch while the outer conductor touches the ground plane.The location of feed point is selected to the patch so that it gives the best impedance match with $50 \Omega$ line. The central conductor is in direct contact with the patch while the rest of part is behind the ground. Hence it minimizes the spurious radiation but the main drawback is that it's not easy task to model the equivalent of probe using the EM tools. Thicker substrates can increase the surface waves and high cross polarized fields. The impedance matching is that point on the patch from the centre where we are getting a $50 \Omega$ impedance and this can be calculated since we know the impedance at the corner of patch. We are using the dielectric material RT Duroid of dielectric constant of 2.2. Impedance at $\mathrm{y}=\mathrm{y}_{0}$ from Patch edge is given as[1]:

$$
\mathrm{R}\left(\mathrm{y}=\mathrm{y}_{0}\right)=R(\mathrm{y}=0) \cos ^{2}\left(\frac{\pi y_{0}}{L}\right)
$$

While the impedance of coaxial line is as: 


$$
\mathrm{Z}=\frac{60}{\sqrt{\varepsilon_{\mathrm{r}}}} \ln \left(\frac{b}{a}\right)
$$

The main advantage of coaxial probe feed is fabrication and matching is easy, and it has low spurious radiation. But, it has problem of narrow bandwidth and more difficult to model, mainly for thick substrates.

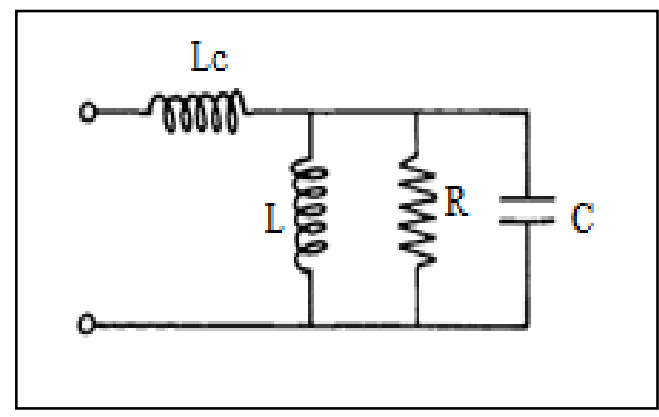

Fig 4: Equivalent circuit of coaxial Patch Antenna

The figure (4) shows the equivalent circuit of coax feed patch where $L_{c}$ denotes the inductive part due to inner conductor.

\section{SIMULATION AND RESULTS}

Table 1-The design Parameters of Microstrip Patch

\begin{tabular}{|c|c|}
\hline \multicolumn{2}{|c|}{ Design Parameters } \\
\hline Operating frequency $\left(\mathrm{f}_{\mathrm{o}}\right)$ & $2.4 \mathrm{GHz}$ \\
\hline substrate height $(\mathrm{h})$ & $1.57 \mathrm{~mm}$ \\
\hline dielectric constant $\left(\varepsilon_{\mathrm{r}}\right)$ & 2.2 \\
\hline thickness of metal $(\mathrm{t})$ & $35 \mu \mathrm{m}$ \\
\hline
\end{tabular}

\subsection{Microstrip Feed Patch}

Using the formula given above, we can find the Patch dimensions which are designed in HFSS.

Table 2- Dimension the Patch antenna

\begin{tabular}{|c|c|}
\hline \multicolumn{2}{|c|}{ Dimension of Patch Antenna } \\
\hline Width of patch & $41.08 \mathrm{~mm}$ \\
\hline Length of patch & $40.55 \mathrm{~mm}$ \\
\hline Length of Quarter line & $24.05 \mathrm{~mm}$ \\
\hline Width of Quarter line & $0.52 \mathrm{~mm}$ \\
\hline Length of $50 \Omega$ line & $15 \mathrm{~mm}$ \\
\hline Width of $50 \Omega$ line & $4.84 \mathrm{~mm}$ \\
\hline
\end{tabular}

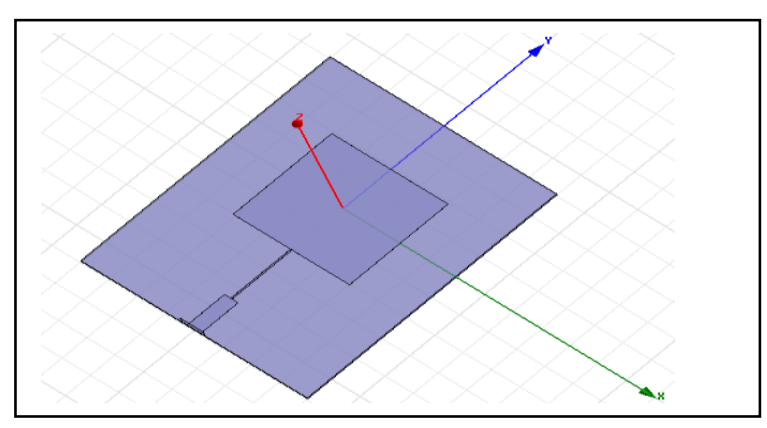

(a)

This figure (a) shows the Microstrip feed patch structure implemented on HFSS.

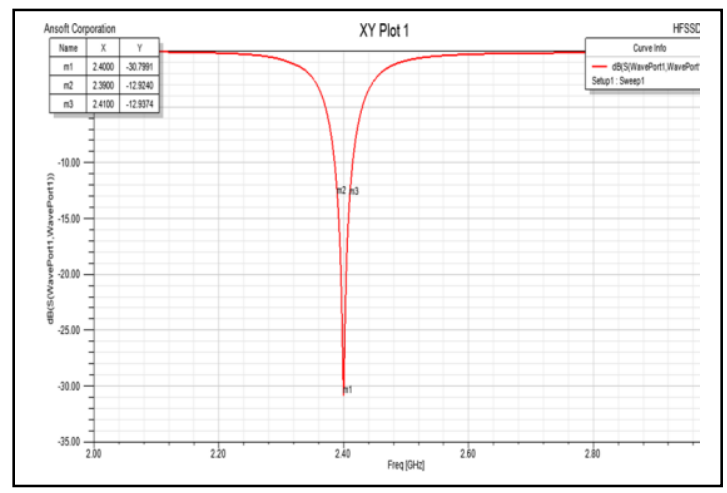

(b)

This figure (b) the return loss of patch in $\mathrm{dB}$ with respect to the frequency. This helps to calculate the impedance bandwidth.

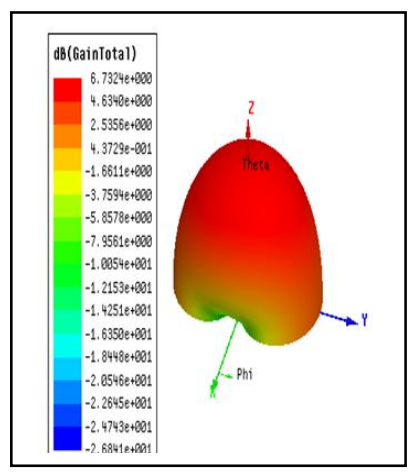

(c)

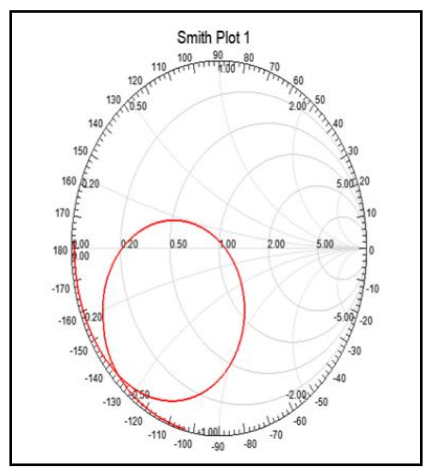

(d)
This figure (c),(d) shows the gain of the patch in the Boreside direction and another figure shows the smith chart plot w.r.t. the frequency. 


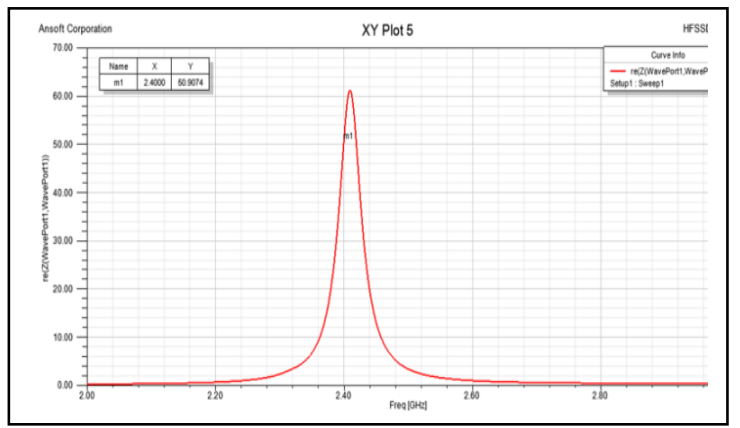

(e)

This figure (e), (f) shows the Real and imaginary part of impedance variation $w$. r. t. to the frequency. The net impedance should be $50 \mathrm{ohm}$ for the best match and the good return loss.

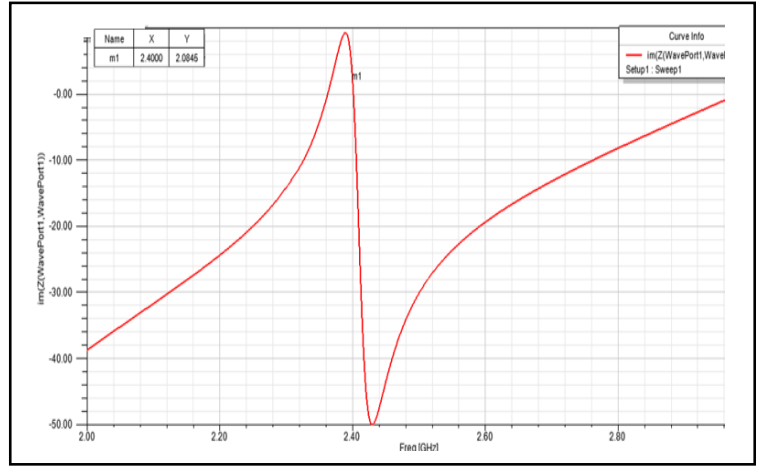

(f)

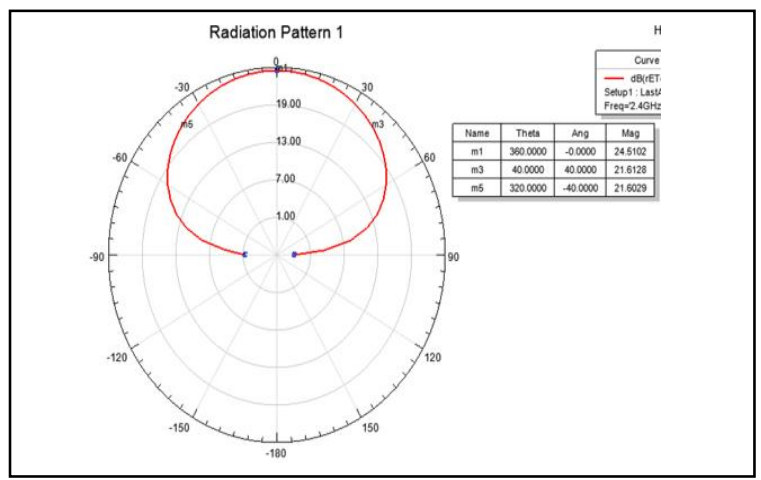

(g)

This figure $(\mathrm{g})$, the $\mathrm{E}$ field variation in the azimuth plane of the patch and HPBW can be calculated from this.

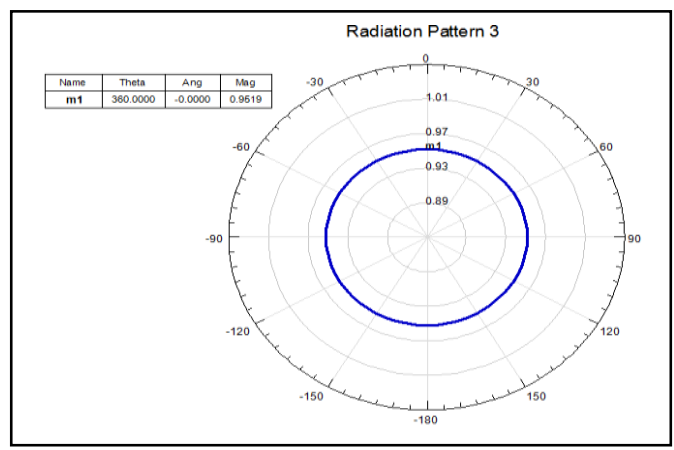

(h)

This figure (h), the radiation efficiency plot of patch antenna

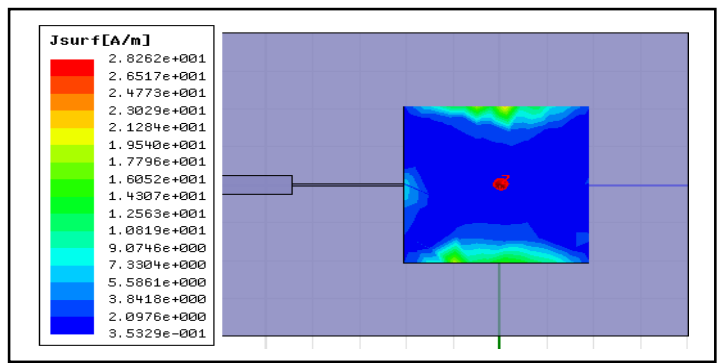

(i)

This figure (i), gives the variation of the surface current density on the patch antenna. It represents the magnitude variation. We can see that the current is maximum at the centre while its zero at the edges.

Fig 5: (a) Circuit diagram of Microstrip feed (b) Return loss (c) Gain (d) Smith Chart (e) Re (Impedance) Plot (f) Im (Impedance) Plot (g) Radiation pattern of $\mathrm{E}$ at phi $=0 \mathrm{deg}$. (h) Antenna Radiation Efficiency (i) Surface Current density on Patch

\subsection{COAXIAL PROBE FEED PATCH}

In the coaxial feed patch antenna, the position of feed is taken as $6.22 \mathrm{~mm}$ from the centre of the patch where the feed impedance is equal to $50 \Omega$.

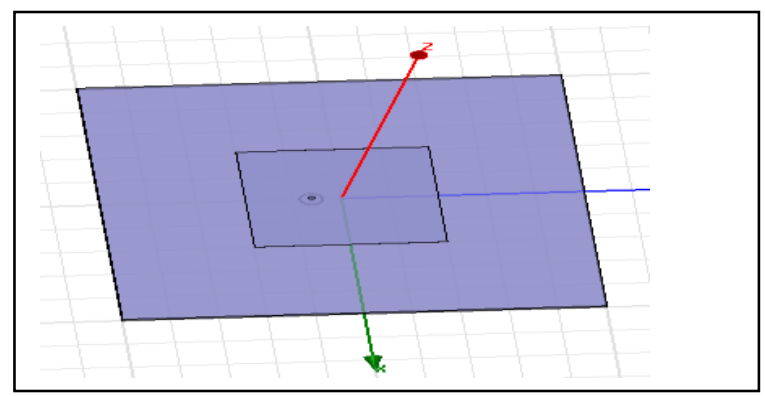

(a) 
This figure (a) shows the Coaxial feed patch structure implemented on HFSS.

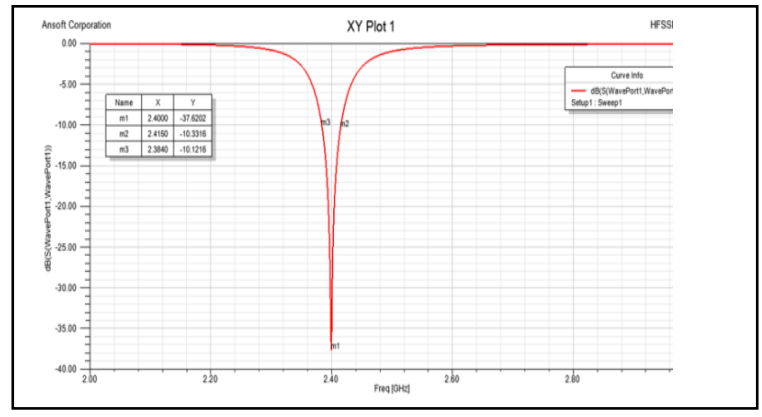

(b)

This figure (b) the return loss of patch in $\mathrm{dB}$ with respect to the frequency. This helps to calculate the impedance bandwidth.

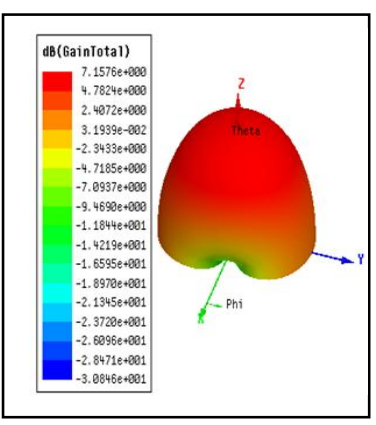

(c)

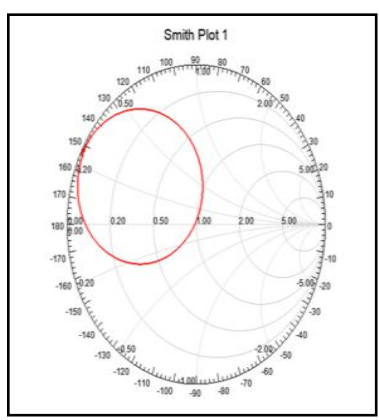

(d)
This figure (c), (d) shows the gain of the patch in the Boreside direction which shows a gain of $7.157 \mathrm{~dB}$ and another figure shows the smith chart plot w.r.t. the frequency.

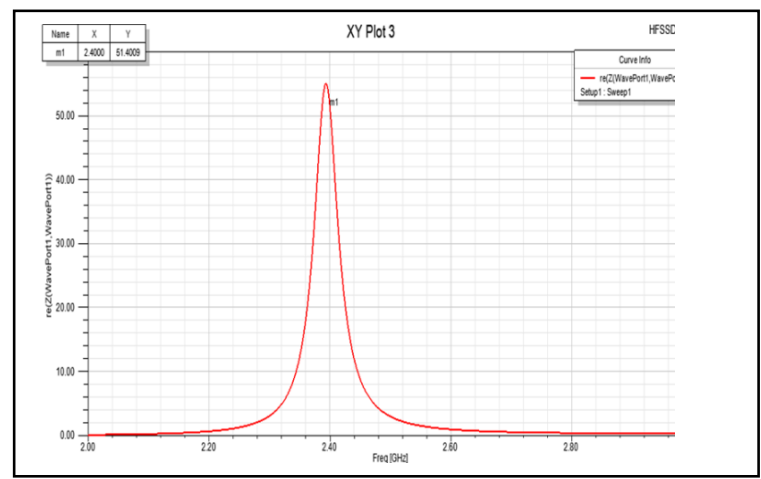

(e)

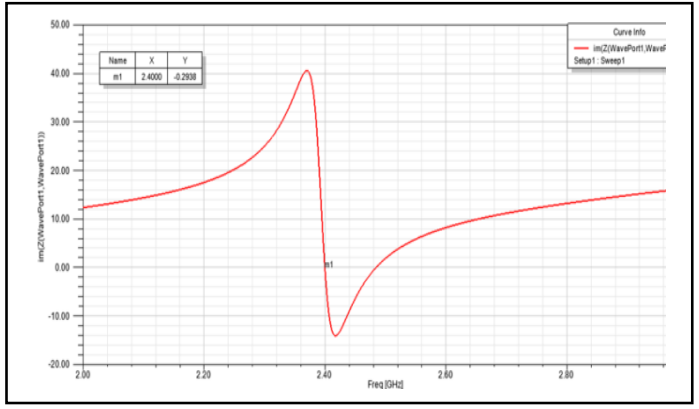

(f)

This figure $(\mathrm{g})$, the $\mathrm{E}$ field variation in the azimuth plane of the patch and HPBW can be calculated from this.

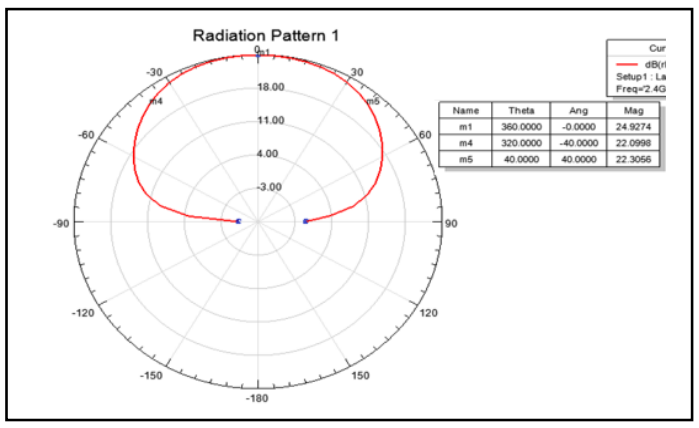

(g)

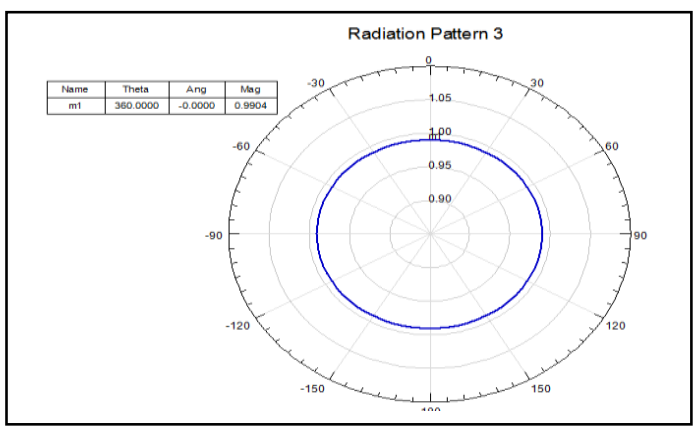

(h)

This figure (h), the radiation efficiency plot of patch antenna

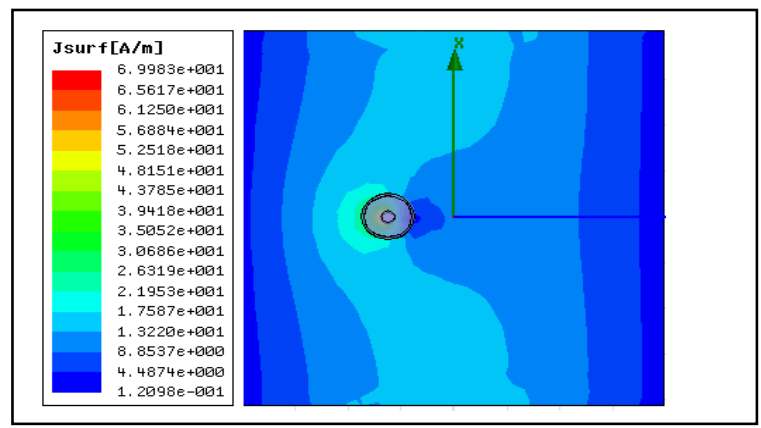

(i) 
This figure (i), gives the variation of the surface current density on the patch antenna. It represents the magnitude variation. We can see that the current is maximum at the centre while its zero at the edges.

Fig 6: (a) Circuit diagram of Coaxial feed (b) Return loss (c) Gain (d) Smith Chart (e) Re (Impedance) Plot (f) Im (Impedance) Plot (g) Radiation pattern of $\mathrm{E}$ at phi $=0$ deg. (h) Antenna Radiation Efficiency (i) Surface Current density on Patch

\section{APPLICATION}

This patch antenna is used for Wifi, WLAN application at 2.4 $\mathrm{GHz}$ frequency for narrow band operation. Since we have used the low dielectric constant material for the fabrication of patch hence the radiation efficiency is good. We can introduce the reconfigurability is our design hence this can be used for two different frequency applications using the same patch antenna.

\section{CONCLUSIONS}

Table 3- Comparison in the Two feeding Techniques

\begin{tabular}{|c|c|c|}
\hline \multicolumn{3}{|c|}{ Antenna Parameters } \\
\hline Types of feed & $\begin{array}{c}\text { Micro } \\
\text { strip feed }\end{array}$ & $\begin{array}{c}\text { Coaxial } \\
\text { feed }\end{array}$ \\
\hline Fractional Bandwidth & $0.83 \%$ & $1.29 \%$ \\
\hline Return Loss (dB) & -30.7 & -37.6 \\
\hline Gain(dBi) & 6.732 & 7.157 \\
\hline $\begin{array}{c}\text { Re(Impedance) @ } \\
2.4 \mathrm{GHz} \text { in } \Omega\end{array}$ & 50.9 & 51.4 \\
\hline $\begin{array}{c}\text { Im(Impedance) @ } \\
2.4 \mathrm{GHz} \text { in } \Omega\end{array}$ & $2.084 \mathrm{j}$ & $-0.29 \mathrm{j}$ \\
\hline HPBW (deg.) & 80 & 80 \\
\hline Radiation Efficiency & $95.19 \%$ & $99.04 \%$ \\
\hline Polarization Purity & Poor & Poor \\
\hline Spurious Radiation & More & More \\
\hline
\end{tabular}

As we got the result in HFSS tool of the simulated patch structure, we can say that this is a narrow band structure having impedance band width very small. We are getting the good return loss for an impedance bandwidth around $20 \mathrm{MHz}$. Gain of microstrip feed is $6.732 \mathrm{dBi}$ whereas the gain of coaxial feed is $7.157 \mathrm{dBi}$. The Half power band width for both the cases is around $80^{\circ}$. The Radiation efficiency of patch is around $99 \%$ for the coax feed whereas $95 \%$ for the micro-strip feed patch structure. The magnitude of impedance is nearly $50 \mathrm{ohm}$ hence we can say that this have a good impedance match with the SMA connector of $50 \mathrm{ohm}$ impedance. The Polarization purity is poor and the Spurious radiation is high.

\section{REFERENCES}

[1]. C. A. Balanis 1982 "Antenna Theory: Analysis and Design" John Wiley \& Sons. 819-873.

[2]. D. M. Pozar, "Microstrip Antennas", Proceedings of the IEEE, vol. 80, no 1, pp-79-91, 1992.

[3]. Ramesh G, Prakash B, Inder B, and Ittipiboon A. (2001) Microstrip antenna design handbook, Artech House.

[4]. G. Kumar and K. P. Ray, Broadband Microstrip Antennas, Artech House, USA, 2003

[5]. James J. R. and Hall P. S. (1989) Handbook of microstrip antennas, Peter Peregrinus, London, UK

[6]. John D. Kraus. Antennas 2nd Edition McGraw Hill International, 1988

[7]. D. M. Pozar, Microwave Engineering, 3rd Edition, John Wiley and Sons Inc.

[8]. S. Zhong, Microstrip Antenna Theory and Applications, Xian Dianzi Technology University, Peoples Republic of China, 1991.

[9]. Edward Jordan, Electromagnetic Waves and Radiating Systems,2nd Edition, Pretince Hall.

[10]. Sinati, R. A., CAD of Microstrip Antennas for Wireless Applications, Artech House, Norwood, MA, 1996.

[11]. Waterhouse, R., Printed Antennas for Wireless Communications, John Wiley \& Sons Inc, 2007.

[12]. Pozar D.M., and Schaubert D.H (1995) Microstrip Antennas, the Analysis and Design of Microstrip Antennas and Arrays, IEEE Press, New York, USA

[13]. Pozar, D.M., Microstrip antenna aperture-coupled to a microstrip-line, Electron. Lett.,vol. 21,pp. 49-50, Jan. 1985.

[14]. Pozar, D.M., Increasing the bandwidth pf a microstrip antenna by proximity coupling, Electron.Lett.,vol. 23, pp. 368$369,1987$.

[15]. Zurcher, J.-F. and Gardiol, F.E., Broadband Patch Antennas, Artech House, Boston, 1995.

[16]. Targonski, S.D., Waterhouse, R.B., and Pozar, D.M., Wideband aperture coupled microstrip patcharray with backlobe reduction, Electron. Lett.,vol. 33, pp. 2005-2006, Nov. 1997.

[17]. Waterhouse, R.B., Rigorous analysis of probe-fed microstrip antennas incorporating parasitic elements to enhance the bandwidth, Progress in Electromagnetics Research Symposium, Seattle, WA, p. 596, July 1995.

[18]. Kin-Lu Wong, "Planer Antennas for Wireless Communications", John Wiley \& Sons Ltd, 2003.

[19]. ZhiNing Chen, "Antennas for Portable Devices", John Wiley \& Sons Ltd, 2007.

[20]. G. Monti, L.Catarinucci, and L.Tarricone, Compact Microstrip Antenna for RFID Applications, Progress in Electromagnetics Research Letters, Vol. 8,191-199, 2009.

[21]. Gonca CAKIR,Levent SEVGI, " Design, Simulation and Tests of a Low-cost Microstrip Patch Antenna Arrays for the Wireless Communication", Turk J Elec. Engin, Vol. 13. No. 1 2005.

[22]. K. Fujimoto and J.R. James, Mobile antenna system handbook, 2ndedition, Artech House Inc., 2001 


\section{BIOGRAPHIES:}

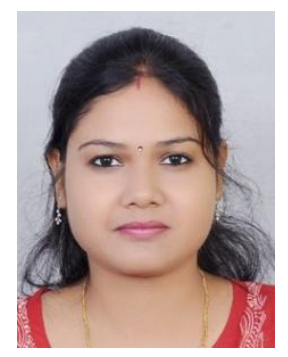

Anchal Verma is presently pursuing her M. Tech. studies in the Department of Electronics and Communication Engg., Amity University Uttar Pradesh, Lucknow Campus. She received her B.tech. Degree in Electronics \& Communication Engineering from Feroze Gandhi Institute Of Engineering and Technology, Uttar Pradesh Technical University, in 2008. She has several online publications in reputed journal and actively involved in the field of Technical Education as a research scholar.

Email id-anchal.verma@student.amity.edu

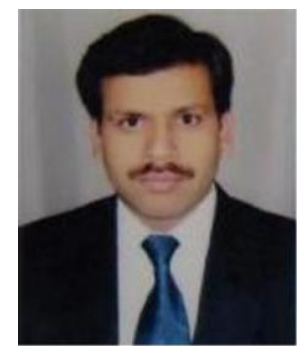

Dr. O. P. Singh, obtained his Ph.D in Electronics Engineering for IT, BHU. He has over sixteen years experience and presently working as Professor and Head Department of Electronics \& Communication Engineering, Amity School of Engineering \& Technology, Amity University Uttar Pradesh Lucknow Campus. He is life member of Indian Society of Remote Sensing (ISRS) and Material Research Society of India (MRSI).He has presented several papers in National Seminar/Conferences and also published papers in National/international Journals. His area of interest includes Microwave Remote Sensing Digital System, Signal Processing.

Email id-opsingh@amity.edu

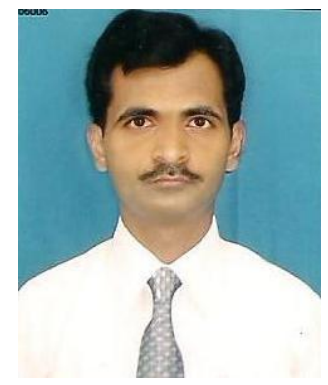

Dr. Ganga Ram Mishra obtained his M.Sc. Electronics degree from Gorakhpur University and $\mathrm{Ph}$. D in Electronics from Avadh University. He has over eleven years experience and presently working as faculty members in Department of Electronics \& Communication Engineering, Amity School of Engineering \& Technology, Amity University Uttar Pradesh Lucknow Campus. He is life member of Institution of Electronics \& Telecommunication Engineers (IETE), Material Research Society of India (MRSI) and member of IET, UK. He was actively involved in foundation of Professional Activity Center IETE Gorakhpur and worked as elected member of IETE Lucknow Center during 2008-2010 and nominated as local center nominee for IETE Students' Forum (ISF) at Amity University Lucknow Campus. He has presented several papers in National Seminar/Conferences and published papers in National/international Journals. His area of interest includes Digital System Design, Microprocessor Based System Design, Signal Processing, Embedded Systems and VLSI Design.

Email id-gr_mishra@ rediffmail.com 